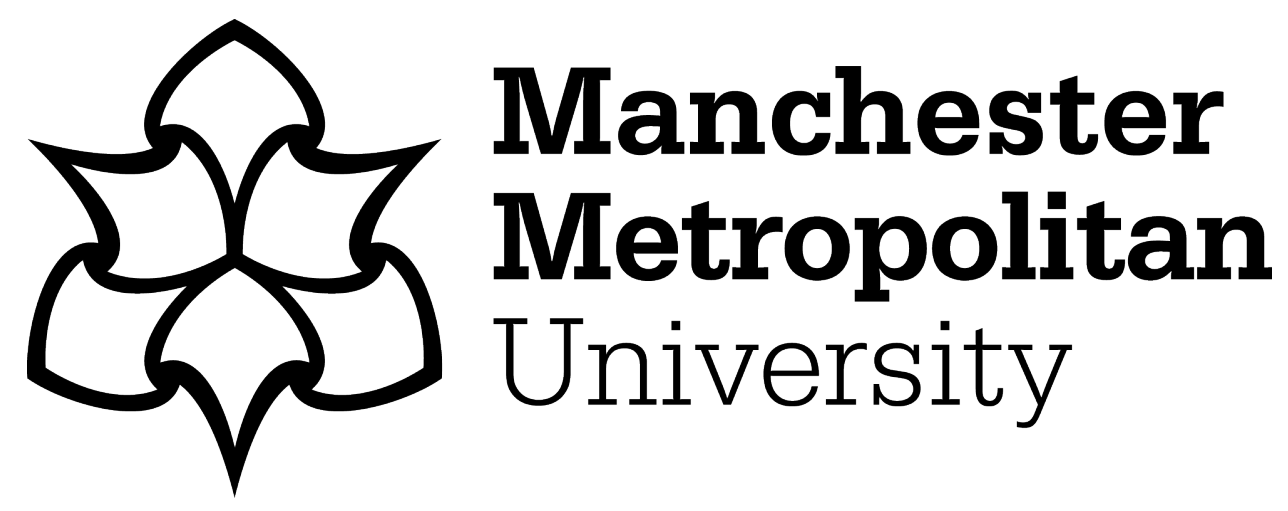

Brown, T and Clarke, D (2013) Institutional contexts for research in mathematics education. In: Third International Handbook of Mathematics Education. Springer International Handbooks of Education . Springer, pp. 459-484. ISBN 9781461446842

Downloaded from: https://e-space.mmu.ac.uk/622352/

Publisher: Springer

DOI: https://doi.org/10.1007/978-1-4614-4684-2_15

Please cite the published version 


\title{
15 \\ Institutional Contexts for Research in Mathematics Education
}

\author{
Tony Brown \\ Manchester Metropolitan University
}

\section{David Clarke}

The University of Melbourne

\begin{abstract}
Mathematics has maintained an enduring image as a field of knowledge lending its resources to many intellectual pursuits and utilitarian enterprises. School mathematics, however, has increasingly learned to respond to a commonly conceived purpose of supplying the world's workforce with the resources needed to support economic wellbeing. The emergent regulation in support of this response has in some instances tempered more humanistic or idealistic conceptions of why we want to study mathematics. What had been introduced to measure school mathematics now defines and polices its boundaries. It has also privileged Western concerns in setting internationalized agenda. Mathematics, mathematics education and mathematics education research, this chapter suggests, are each conceptualized according to their location, reflecting and shaping each other, yet with each being governed by slightly different priorities. It is argued that schooling is increasingly shaped and judged by its perceived capacity to deliver success in terms of international competitiveness linked to economic agenda. This results in school mathematics being shaped to meet assessment requirements. The chapter shows how research increasingly finds its terms of reference set according to measuring delivery in these terms. It also shows how researchers become complicit in promoting particular conceptions of teaching and in constructing the field as an ideological battleground. Such complicity, it is suggested, combined with the relative insularity of the field, prevents us from occupying other worlds that might define us and serve us in different ways. The chapter concludes with a consideration of the prospects of research in mathematics education and the extent to which this activity is enabled or restricted by existing institutional contexts in re-shaping its ambitions to engage with the diversity of future needs.
\end{abstract}

Keywords: mathematics education, research, institutional context, ideology, curriculum

\section{Mathematics, Mathematics Education, and Mathematics Education Research}

Is mathematics defined by local conditions or can it be understood more universally as spanning nations and generations? Mathematics has maintained an enduring image as a field of knowledge lending its resources to many intellectual pursuits and utilitarian enterprises. School mathematics, however, has increasingly learned to respond to a commonly conceived purpose of supplying the world's workforce with the resources needed to support economic wellbeing. Research intended to inform the practices of mathematics classrooms has often reflected local interpretations of this fundamentally economic agenda. Since the advent of international comparisons, governments have been jockeying for a better position in the resulting league tables. The success of particular school systems in international testing programs such as the OECD Programme for International Student Assessment (PISA) or Trends In Mathematics and Science Study (TIMSS) has been variously interpreted. Good performance in these league tables has 
sometimes been taken as being indicative of wider economic competitiveness. Yet such comparisons can transform the content of what they compare.

TIMSS contributes to the misrecognition of terrain where global politics motivates policy makers to apply national security responses to education. The assessment casts students as passive, nameless metaphors of national economies, whose performance in school will predict the future relations among nations. (Thorsten, 2000, p. 72)

Governments and the people they govern have been seduced by the appeal of raising standards in a statistically defined world. What had been introduced to measure school mathematics now defines what it is and polices its boundaries. This regulation has tempered more humanistic or idealistic conceptions of why we want to study mathematics. It has also done much to alter how we understand research in the area.

Howson and Mellin-Olsen (1979) documented some of the history of mathematics' evolution as a school subject for which, since the beginning of school mathematics education, the subject was stratified according to the type of student concerned, and the expectations held for them. Over the past few decades, though, the bounded vision of the measurable mathematics preferred by international testing programs (whether TIMSS or PISA), a climate of competition has been created in which nations compete for status and governments take credit or apportion blame according to these quantifications of student achievement. Among the consequences of international competition and the attendant commitment to national typification we suggest that national means of performance are given priority over the local inequalities they conceal. The success of less affluent nations in optimizing the effectiveness of their minimally resourced educational systems may go unrecognized. More informed analyses of the data generated by international testing are capable of pointing to idiosyncrasies in school systems that address, ignore or even amplify the educational difficulties experienced by particular population sectors. Our interest in this chapter is less to bewail the misuse of research in mathematics education as to examine the institutional contexts that influence the form taken by that research and explore the consequences of that influence.

Mathematics, mathematics education and mathematics education research are each conceptualized according to their location. It will be argued that they reflect and shape each other, with each being governed by slightly different agenda. For example, the assessment of school mathematics through filters such as international tests of student performance has changed the priorities of school mathematics in many countries. These changes have in turn had an impact on how the field of mathematics education research is conceived internationally. The international industry that has arisen around the assessment of student mathematics achievement has simultaneously enacted and shaped local and international conceptions of accomplished practice in mathematics and in mathematics education. Research is judged by its perceived capacity to deliver success in the prescribed terms.

For instance, the goal of comparative international measurement of student mathematics achievement is sometimes conceptualized as the raising of standards. These standards, however, result from a very specific conception of mathematical learning, often based on what US policy makers have deemed to be important through their reference to TIMSS in evaluating performance in US schools (see Bishop, 1990). Other countries have readily subscribed to these priorities, apparently with minimal questioning, or because the priorities have become the international currency to which their governments can reference their own schools' achievements in electoratefriendly terms. The assumptions about what is valuable have been encrypted into the measuring devices themselves. The results are then subject to considerations of alignment with valued mathematical performances, the affordances and limitations of the measuring devices (the test), and assumptions about levels or composition of achievements appropriate to particular age cohorts. Mathematical activity or performance, in school, workplace and other settings, is the medium by which the purposes of mathematics education are realized. Mathematics education 
research meanwhile draws its identity from an interest in optimizing and informing both mathematical activity and mathematics education. The focal concern of this chapter lies with those institutions that provide the context and the agenda for mathematics education research.

The scale of international research efforts and the political status of the findings have popularized a distinctive genre of mathematics education research. Accordingly, the image of the lone researcher finding out how mathematics might be taught has been eclipsed by more collective conceptions of mathematics in schools and of the research tasks developed to investigate and inform educational practice. These conceptions result from shifts in pedagogical attitudes, such as those attitudes manifest in the reform movements in the United States, China and Singapore, which combine reform zeal with very differently targeted initiatives. Associated activities can include the working through of regulative demands on curriculum definition, as in China and Australia, and the changing roles of universities in preparing teachers, as in the United Kingdom and Singapore. Researchers continue to produce knowledge and this knowledge is open to appropriation by those seeking to maintain current ideologies or by those seeking to critique and contest current ideologies. For example, Piaget and Vygotsky have been variously deployed to underwrite constructivist reforms in the United States. Freudenthal's work has been marketed as an alternative school mathematics scheme. Yet knowledge is a function of the world that produces it, which can prevent us occupying other worlds that might define us and serve us in different ways. International research has the potential to afford access to alternative visions of curriculum and practice, but filters the study of such alternatives through the normalizing demands of common measurement instruments and the use of English as the lingua franca of international education and educational research.

There are difficulties for research in exploring good practice when governments are defining what good practice is according to policy driven priorities and budgetary constraints. Research carried out according to the preferences of these governments is frequently about supporting "improvement" within the current model rather than being about producing and testing new models. Researchers can become subservient to the latest governmental vision. We suggest that such institutional contexts (a) determine the criteria by which good practice is recognized; (b) prescribe the manner in which good practice can be researched; and (c) frame and constrain the channels by which research can inform the promotion and realization of "evidence-based good practice." Central to this discussion is the determination of what constitutes evidence for the purposes of informing practice and generating policy. This shaping of the direction of research determines what mathematics and mathematics learning are considered as legitimate objects of that research.

Insistence on the universality of mathematical activity, however, represents a denial of the heterogeneity that characterizes mathematics and the way in which it is shaped to fit diverse locations. Mathematics means different things to different people, where groups may prefer particular perspectives that solidify in certain communities, according to culture, ethnicity, affluence, gender, and social class, as alternative contexts. Mathematics is held in place by its appearances in specific locations (particular pedagogical forms, representations in popular media, its use in accountancy procedures, etc.). We may ask, however, what remains if we take away these specific examples of localized cladding that at once disguise mathematics and make it recognizable and functional in those specific locations? There may be nothing left. Mathematics resides in its localized appearances addressing specific demands. Yet, not all voices or ways of life are equal on the international stage. The tension between local priorities, values and needs and the normalizing demands of international comparability make clear the sensitivity of mathematics education research to the demands of context.

Research in mathematics education has increasingly turned to issues of context, while being situated itself in many contexts. Far from being the province of the lone researcher, research these days takes place increasingly in small and large teams, usually but not always at universities, and 
frequently drawing membership from several educational contexts and traditions. Each stakeholder group participant in research brings its own agenda: governments, funding agencies, school systems, community groups, business, universities, research centres, research teams, teachers, students, parents, and individual researchers. But, most importantly, research takes place within communities of people governed by collective arrangements that define, regulate and normalize the practices that take place. This chapter examines the benefits and drawbacks, the affordances and the constraints, of these institutional contexts for the training and education of researchers but chiefly for the development of the field itself. Above all, it seeks to show how there are political dimensions that pertain to the practice, funding, researching and training for mathematics education, and which shape what it is. For research to be meaningful and useful it must examine the ways in which these political dynamics constitute the basic entities that make up mathematics education, namely teachers, students and mathematics itself (Otte, 1979).

The chapter commences with a preliminary account of the wider domain of mathematics education research with respect to its institutionalized contexts across and within nations, and the tools that they employ (international achievement tests; the criteria for funding deployment; conceptions of mathematics curricula). A useful approach is to examine the domain in relation to the ideological movements that legitimize mathematics as a school subject and the research carried out in this area. We have anchored this discussion on an account of "reform" mathematics as it has been conjured in the United States and, more recently, in China; as an ideology acting through the social practices in each country and beyond to produce conceptions of mathematics and its teaching. The chapter continues by examining the definition of the field of mathematics education in relation to its manifestation in specific institutional contexts: curriculum development and evidence-based policy initiatives, publication networks, academic networking and research community definition and the training and education of researchers. The chapter concludes with a consideration of the prospects of research in mathematics education and the extent to which this activity is enabled or restricted by existing institutional contexts in re-shaping its ambitions to engage with the diversity of future needs.

\section{"Reform" as a Context for Mathematics Education Research}

There is a common assumption that research in mathematics education is about informing movement towards some improved conception of teaching. But how might we conceptualize improvement? Can we agree on some set of shared aspirations? Or, alternatively, could we agree on a greater tolerance of difference? Collective movement might be harmonized towards "improvement," whether that is about being more the same, through curricular consensus or standardization of achievement measures, or more responsive to local conditions and thereby more diverse. Different goals require different approaches. What mechanisms, for example, might allow individuals to join together in such a way that a collective vision is conjured and coordinated practice is realized? What mathematics education research might inform practice within such collective arrangements? The teaching of school mathematics typically takes place within some curricular structure set for a particular community of people. The scope for individual teachers to interpret their task is tempered by their susceptibility to having their work evaluated according to local criteria. That is, teachers serve administrations aspiring to some model of teaching and take steps to align their practice with those aspirations. In turn, research is often commissioned to support or enhance practice consistent with that agenda.

Modern conceptions of "reform" as a notion within mathematics education research have developed new meanings linked to the guidelines of the US National Council of Teachers of Mathematics. Mathematics educators in the United States, the United Kingdom, and Australia have associated the term "reform" with the transition from a transmission to a constructivist pedagogical approach (Fennema \& Nelson, 1997) and curricular reform in China, Korea and 
Singapore is now taking a similar path. By comparison, Japanese mathematics educators were making an effort in the 1960s and 1970s "to develop ways of making students discover new ideas and construct knowledge on their own" (Hino, 2007, p. 508). The result of these Japanese efforts was the development of a lesson structure called "structured problem solving" that has been the subject of much subsequent research (Hino, 2006; Sekiguchi, 2006; Shimizu, 2006). What is perceived as abrupt transformative reform in many countries is seen as the continuation of a longterm process of research and development in Japan. This contrast is important because it suggests that the reception accorded to the same instructional (or curricular) advocacy will differ according to the educational history of the community.

Constructivism, as a conception of learning, though centred in the United States, dominated international mathematics education research for some two decades (Steffe \& Kieran, 1994; Brown, 2001). The pedagogy associated with constructivism involved the promotion of student agency and active engagement in advancing their own learning, through "genuine mathematical problems for students to solve" (Lloyd, 1999, p. 228) with a focus on "conceptual understanding" (Wilson \& Goldenberg, 1998, p. 269). Research in the area had sometimes been conceptualized as tracking progress towards some improved state of affairs (Simon \& Tzur, 1999; Tzur, Simon, Heinz \& Kinsel, 2001). Other studies focussed on how teachers responded to curriculum changes. These studies centred their analyses on individuals shaping their practice in response to the perceived reform agenda (Remillard \& Geist, 2002; van Zoest \& Bohl, 2002). Many of the authors identified and openly subscribed to this agenda. That is, the researchers were complicit in the promotion of a particular conception of teaching: inclined towards researching its optimization rather than towards the development of any form of critique. This is not an irrational position: if the efficacy of an instructional approach is demonstrated by research, then further research into its optimization is a logical next step. In the context of educational research, this simple rationality can be qualified by questioning: (a) the legitimacy of generalizing such instructional advocacy to all settings; and (b) the clarity and uniformity with which the advocated practice and associated theory is understood, even by those advocating its implementation. Educational advocacy - that is, reform - is always subject to contingencies of context and of consensus.

Not surprisingly, such reform did not offer a trajectory with universal appeal or applicability. There were widespread disputes within the USA itself, centred on debates that have come to be known as the "math wars." These disputes have since been replicated in other countries (in China, for example) in response to similar curricular initiatives. The "inquiry" methods associated with constructivist reform, characterized by greater learner and teacher autonomy directed at conceptual understanding, have been resisted by more traditional teachers, who preferred an emphasis on computational skills, and by some mathematicians, who saw in the new approach a loss of mathematical rigour. Similar battles continue to be fought as other countries, such as China and Korea, implement national mathematics curricula that embrace "reallife and open-ended problems" in curricular contexts dominated by examinations (Cai \& Nie, 2007).

More theoretically grounded objections to constructivism pointed to the confusion caused by interpreting a theory of learning as a theory of instruction. Disputes over the effectiveness of new instructional approaches have been compounded by lack of agreement on what constitutes accomplished mathematical activity. Research in mathematics education became a weapon of the math wars, to be used (as in Andrew Lang's happy phrasing) "as a drunken man uses lampposts for support rather than illumination" [from: http: http://www.brainyquote.com/quotes/authors/a/ andrew_lang.html]. Since researchers in mathematics education are simultaneously members of the mathematics education community, they become complicit in the construction of the field as an ideological battleground and in the use of research as a weapon in that war. Perhaps it is inevitable that education, as a value-laden and culturally encumbered field, should be so prone to ideological division. It is not only unreasonable, but actually a misrepresentation of the nature of 
research, to expect educational researchers to adopt a form of ideological neutrality. The activities of mathematics education researchers are just as ideologically, politically, historically and socially situated as any other members of society: that is, just as subject to the influences of context.

Research must address not only the basic questions of teaching efficacy and learning, but also the processes and impediments by which any research-based advocacy might be actioned. For example, a few researchers sympathetic to constructivism noted resistance in some quarters, such as "veteran" or "traditional" teachers who were unable to shift so fundamentally in terms of their beliefs in what it is to be a teacher (Cohen, 1990; Lloyd, 1999; Wilson \& Goldenberg, 1998). The inquiry methods would also have been less acceptable in many Eastern or Pacific cultures, where curricula, teacher/student roles and the collective good are defined differently (Brown, Devine, Leslie, Paiti, Sila'ila'i, Umaki \& Williams, 2007). Further, the alleged autonomy understood within the "reform" agenda conflicts with the reality teachers have come to accept in many countries, assessed as they are through legislative documentation and recognized through the filter of their compliance with this. Such differences are profoundly cultural and reflect histories of educational practice that pose substantial obstacles to any reform movement predicated on autonomy, agency, dialogical reasoning and the legitimacy of contesting prevalent beliefs. The role of research and the researcher in such contested domains becomes itself the matter of debate and the authority of research and the credibility of the researcher will be equally acclaimed and decried by vested interests.

In England, for example, student-centred pedagogies emphasizing problem solving, investigations and project work dominated curriculum reform agendas some 30 years ago. The rhetoric of this tradition was largely commensurate with constructivism. A later backlash in England resulted in prescribed curricula for both teachers and students in which student-centred approaches became tightly structured. Reasons cited for this backlash included right-wing politicians - such as Kenneth Clarke, a Conservative Minister of Education - claiming that given difficulties with teacher supply the average teacher could not teach to such high-minded ideals. Left-wing commentators, meanwhile, argued that aspirations to child-centred approaches merely replaced overt regulation with a form of covert regulation (Walkerdine, 1984). The heightened status of student agency was accompanied in several Western school systems by a commensurate reduction in the importance attached to teacher agency (Chazan \& Ball, 1999; Clarke, 1994; Lobato, Clarke, \& Ellis, 2005). The prioritization of "higher-order thinking, self-reflection and self-regulation" in countries such as Singapore (Fan \& Zhu, 2007) has been identified with the problematization of "traditional teaching" and the implicit devaluing of established tenets of teacher expertise.

\section{The Ideological Bases for Improvement}

Conceptions of "improvement" can be very localized. Trajectories of improvement do not apply across all people and all phases of development. Success depends on the criteria one uses for judging success. Many alternative criteria have been entertained in recent years, each governed by their own respective and reasonable assumptions. Relative positions on TIMSS and PISA league tables have encouraged school systems and funding agencies in the United States to adapt mathematics textbooks from Singapore for American use and to appropriate Japanese "lesson study" as a professional development tool in the hope of emulating the achievements of mathematics students in Japan and Singapore. Yet the same league tables are not interpreted in Singapore or Korea as demonstrating unequivocal educational success, where new value is being placed on creativity, imagination, and problem solving ability. Lin (2010) pointed out that Hong Kong, Korea, Japan and Taiwan, who performed well in TIMSS, "showed very poor[ly] in learning interests and self-efficacy" (p. 85). PISA has attempted to give assessment recognition to the situated nature of mathematics activity to a greater extent than TIMSS (Askew, Hodgen, 
Hossain, \& Bretscher, 2010). The attempt within international student achievement initiatives such as PISA to honor the situatedness of mathematical activity within an international testing instrument is wholly commendable. Of course, this same situatedness renders attempts at crosscurricular measurement of student mathematical performance somewhat problematic (see Clarke, 1996). The implicit recognition that mathematics can only be assessed "in use" and that such use implies a context, reflects the underlying assumptions of the Dutch Realistic Mathematics Education curriculum (De Lange, 1987), among others. The consequences of integrating such a perspective into an instrument intended to measure student mathematics achievement internationally can be seen in the observation that "national rankings on TIMSS and PISA differ substantially" (Törner, Schoenfeld \& Reiss, 2007, p. 353). It is clear that "improvement" cannot be defined in absolute terms.

\begin{abstract}
In a special issue of the journal Educational Research and Evaluation, Cheng and Cheung (1999) provided a critique of a series of articles addressing the general theme of "TIMSS in a Western European Context." Their critique raised several concerns: (i) Challenges to the validity of country ranking; (ii) Problems in relevance of TIMSS to national curriculum; (iii) Methodological limitations; (iv) Lack of high quality process data at classroom level; (v) Lack of contribution to theory building; and (vi) Limited policy implications. The culmination of Cheng and Cheung's argument was that limitations and methodological concerns with TIMSS meant that "the policy implications for improvement of educational practices are inevitably quite limited" (Cheng \& Cheung, 1999, p. 233). Given all the issues raised above, it appears that there has been sufficient consistency in the concerns raised about TIMSS to make the policy recommendations problematic. (Clarke, 2003, p. 174)
\end{abstract}

As research and the framing of policy and curriculum become more distant from the activities of the classroom, there is always a cost in the form of local preferences being suppressed resulting from one-size-fits-all suppositions. Generalized consensual aspirations, framed at the level of the state, the country or globally, lose local relevance, and alignment with them is not always so easy to grasp in the immediacy of everyday practice. There is a need to build a theoretical frame that accommodates alternatives to consensual aspiration. Utilization of such a frame would have significant impact on the way research into student achievement and instructional effectiveness was conceived and conducted. To consider alternatives to consensus is to undertake a form of ideological reconstruction. "Improvement," "success" and "quality" become pluralities contingent on context, rather than singular prescriptions.

Recent neo-Marxist theory has questioned notions of human progress being shaped by ideals relevant across all communities (Mouffe, 2005). This is hardly a radical proposal. Mathematics education, for example, might be best seen as supporting the needs of the students concerned. These needs would be culturally dependent, with each country basing its curricular aspirations on alternative conceptions of mathematics according to local need. Yet, international comparative testing has resulted in many countries teaching to those international tests, matching the style and content preferred by certain Western countries. Both curriculum content and styles of teaching have been adjusted to meet this model. For example, in the name of conformity, the United Kingdom has sacrificed its earlier facility with problem-solving approaches. Since problem solving is not assessed focally within TIMSS, this has resulted in problem solving being less common in schools (Askew, et al., 2010). And recent policy has been directed towards enabling British children to be successful in the sorts of questions one finds in TIMSS Although England succeeded in moving from 18th to 7th position on TIMSS in 2007, it dropped in its rankings from 8th to 25th on the more problem focussed PISA in 2006 (Brown, 2011; Department of Education (DfE), 2010). Tea- pickers in Sri Lanka meanwhile do not get an education suited to their local needs. The curriculum they have been obliged to follow is governed more by "internationalized" objectives than by the skills that would support the local economy. And, for those who succeed, this usually translates into a move away from their local area to work in a city, within the country, or beyond. The education intended to enable graduate mobility functions to enforce it. 
Laclau (2005) has rejected the notion of the "people" as a collective actor, and, by extension, the same could apply to the possibility of a research "community" or a set of governments being able to define a common interest with regard to the purposes of school mathematics. For example, to what extent is it possible for the mathematics education research community to assume some consensus in its purposes? Examination results, facility with mathematics and enjoyment of mathematics do not always pull in the same direction (Pampaka, Williams, Hutcheson, Wake, Black, Davis \& Hernandez-Martinez, in press). Conceptions of graduate competencies will vary from school system to school system as mathematics curricula attempt to anticipate vocational and personal capabilities likely to be required by graduates.

Instead, Laclau has examined the nature and logics of the formation of collective identities and suggested that such collectives can be seen as being held together through identification with specific populist aspirations. In mathematics education we might reference our activities to raising standards, making children happier, supporting the economy, or building richer mathematical experiences. Mathematics would then be shaped according to how it could be read against such aspirations; a quantifiable version of mathematics so that a standard can be shown to have been raised, an aesthetically pleasing version of mathematics for those more concerned with the beauty of mathematics, etc. Group affiliations might be centred on particular shared values or beliefs. Research design will reflect populist aspirations and mirror societal norms and cultural values, since society's rewards (e.g., funding) will reflect society's values. Government grants may be awarded to those promising to advise on how standards could be raised across a population. Self elected research time might be directed at sharing with other like-minded people the intrinsic pleasures and aspirations of the individual's own teaching. The essential point is recognition of the correspondence between values and practice and the willingness to countenance and accommodate a diversity of motives to undertake research.

Some years ago, Althusser (1971) focussed on how the individual understands herself through ideology. Here an ideology is understood as a specific conception of life, a particular version of common sense. One can only inspect an ideology from the perspective of another ideology, "we are 'naturally' in ideology, our natural sight is ideological" (Žižek, 2008, p. xiii). We always occupy an ideologically derived position. We never have the luxury of speaking from outside an ideology. Althusser described schools as an instrument within the "ideological state apparatus." Here schools are seen as a hegemonic device through which the preferred ways of the state are disseminated with general consent. For many pupils and their parents, progression through school is an ideological movement to which they are readily mobilized. Sensitivity to such perspectives can focus research attention on the investigation of inequity. Mathematics and mathematics education have roles in the creation or maintenance of power differentials. These reflect societal norms or established social divisions along socio-economic lines. The role of mathematics in the entrenchment of such narratives of social reproduction has been variously studied (Anyon, 1981; Boaler, 1997; Sztajn, 2003).

Of course, the dominance of such hegemonic societal structures can act to impede any critical function that research might serve. To be published in a reputable journal a research article must typically position itself in relation to existing work and be cast in a form recognizable to a mainstream audience in the field. That is, the tools of the established order must be used to argue for anything new. There is a dynamic between the societal constraints that research might legitimately deconstruct and the action of those constraints to inhibit such critical research. This dynamic is at the heart of the dialectic whereby research becomes complicit in the structuring and maintenance of the systems it might inform. For example, research in mathematics education on gestures, teaching techniques in fractions, or the promotion of group work, may normalize the assumption that adjusting teacher classroom intervention is the main tool of mathematics education, rather than say curriculum reform, adjusting social inequalities, setting teacher education programs, etc. Research participates in constructing the boundaries of its own practice. 
It is not only research as an endeavour that is seen to reflect the institutional context in which it is undertaken. Education, Mathematics, and Mathematics Education continue to evolve in ways that reflect their cultural-historical origins. The structure of a discipline such as sociology, for example, reflects its cultural-historical origins and cannot be understood without recognition that it was formed within the culture of imperialism, and embodied an intellectual response to the colonized world (Connell, 2007). Research in Mathematics Education finds itself inheritor of particular views regarding the aspirational goals of education, the legitimacy of curricular partitioning, and the role served by research to understand and optimize the realization of those goals in specific cultural settings. Within such a framework, conceptions of improvement are predetermined to a significant extent, circumscribing the capacity of research to critique the structures from which it draws its identity.

Althusser was not persuaded by consensual aspirations where difficulties are ironed out. $\mathrm{He}$ saw the supposition that you could get to a consensual ideal beyond conflicting ideologies as the biggest ideology of all. The individual may recognize herself in some ideologies but not others. But, there is always a gap in this identification, a distance between the person and the story in which she sees herself. This gap stays there. For example, some American teachers may truly believe that they are subscribing to the reform agenda and following such approaches in their practice, whether or not others see it this way (Cohen, 1990). But, at the same time, some other American teachers may be sceptical about reform projecting them higher up the international league tables or they may not even agree with that ambition. Yet, both groups find their working practices defined and evaluated in line with that agenda, securing compliance at a practical level. Brown and McNamara (2011) have provided an account of how trainee and new teachers in the United Kingdom begin to include official curriculum descriptors into accounts of their own practices as they move through the accreditation process. The study demonstrated how teachers in England were subject to the policy framework and the terminology it employed. Their validity, professionalism and identities as teachers were understood through the filter of their compliance with this regime.

The purpose of these examples is to demonstrate that judgments of effective practice or program success, or of any other outcome that might provide a focus for educational research, are contingent on the value system structuring the construction, selection and processing of data. These value systems are determined by the context in which the research is conducted. In such circumstances, we may ask whether it is appropriate to celebrate any supposed "improvements" in the quality of mathematical learning. Such "improvements" may simply be indicative of success in the administration's project of convincing the public that the administration's understanding of mathematics is the correct one and, for example, that the content of standardized tests define what mathematics is.

American, Chinese, or any other "reform" functions as an ideology, in Althusser's sense, a specific version of common sense, insofar as it determines the key parameters shaping discussion relating to curriculum innovation. In many instances of mathematics education research, "reform" functions as a supposed consensual aspiration. However, even within each culture: "Based on their concepts of students' needs, teachers select which parts of the reform documents are appropriate for their students," which translates as "children from upper socioeconomic backgrounds get problem solving, those from lower socioeconomic backgrounds undergo rote learning" (Sztajn, 2003, p. 53). These narratives of social reproduction have been regularly revived in research studies from Anyon's (1981) seminal study to Boaler's (1997) more recent analysis. International research assists us to situate such local variation within the parameters of national boundaries, compulsory schooling infrastructure, economic status and a host of other societal assumptions. International perspectives help us guard against the temptation to overgeneralize the regularities and repetitions that we find in local curriculum reform research and to 
recognize how the dictates of locally dominant ideologies can over-determine the processes and outcomes of our research.

\section{Curriculum Development Initiatives and Evidence-Based Policy}

Mathematical learning in schools cannot be understood fully in terms of individual students encountering idealized mathematical objects. Those objects are formed across a much broader context, and can be understood in many different ways. The "meanings circulating in the classroom cannot be confined to the interactive dimension that takes place in the class itself; rather they have to be conceptualized according to the context of the historical-cultural dimension" (Radford, 2006, p. 23). Mathematical objects in a school context are typically defined in relation to a curriculum that prescribes roles for students and teachers. The extent to which such role definitions are culturally and linguistically determined is only now becoming recognized (Clarke, 2010; Brown, 2011). The actions of teachers and students are designed, recognized and assessed according to how they conform to these definitions. This pedagogical housing of mathematics influences the objects that are studied. The housing sets the conditions for learning and the resulting apprehension of mathematics.

More generally, teacher capabilities are not merely dependent on their "delivering" mathematical ideas. The capabilities derive from a broad range of factors. The picture is much bigger. For example, the setting of policy to bring about widespread adjustment to teacher practices towards raising "standards" or national test scores is a persistent aspiration, so often disappointed (Sammons, Day, Kington, Gu, Stobart \& Smees, 2007). Policy makers do not work to a consistent agenda in governing school mathematics, and other stakeholders, such as, advisory groups, regulators, trainers, research and development funding agencies, and potential employers and universities, work according to a variety of perspectives and priorities. At the risk of sounding repetitive, all stakeholders in the mathematics education research endeavour contribute to that endeavour in ways that are highly context-specific and mutually constitutive.

Curriculum decisions are thus divided and shared between these various stakeholder groups, which do not necessarily see eye to eye, resulting in potential disjunctions between policy formulation, implementation by teachers and the conceptualizations made of such implementations by researchers (Saunders, 2007; Whitty, 2006). In addition, much research effort is dissipated across countless small studies from which it is difficult to produce a coherent picture. As a consequence, the theoretical underpinning of such processes has been somewhat fragmentary, sometimes switching between cognitive psychology at the level of the individual student learning mathematics, to an array of policy sciences and budgetary-led political expediency at the macro level. And these various areas of work each have their own specialists, who rarely meet with specialists from other areas to swap notes. The fragmentation of the education community into specialist groups poses a challenge for the development of either an integrative or a normative narrative of curricular reform, evaluation or policy development. For the moment, the best we can hope for is that each ideologically or theoretically situated research narrative is, at least, internally coherent and transparent with respect to its underlying principles and the processes of its gestation. This gives research, evidence and evidence-based policy a contingent character unlikely to meet political demands for generalizability.

How then might we conceptualize the role of research in supporting curriculum development? Much research in the field of mathematics education is targeted at individual teachers or teacher educators, from the perspective of how they might adjust their individual practices with students, yet at the same time an array of policy interventions split between diverse stakeholders operate in the wider domain. Might alternative perspectives or points of leverage offer more effective models of curriculum change? How might we conceptualize mathematics 
education research having an impact on populations of teachers through affecting policy decisions?

Research is often predicated on identifying deficiencies in current practices as part of a rationale for implementing a new approach. Hargreaves (1996, p. 5) has rather optimistically suggested that educational research must demonstrate "conclusively that if teachers change their practice from $x$ to $y$ there will be a significant and enduring improvement in teaching and learning." Hence, a history of research would be characterized as a series of projects, papers and books, with many arguing the case for some sort of improvement against various priorities. Yet looking back at any one time it is not easy to argue how we might assess retrospectively the nature of this cumulative improvement over any given period of time. It is quite difficult to provide evidence of improvement except in narrow terms. With the introduction of any new initiative there comes an implicit assumption that it will bring improvement over the previous regime. Yet priorities are not always consensual and evaluation strategies change over time. Alternative versions of history craft their heroes, objects and time phases differently. The term "improvement" can be understood in many different ways and resists stability across time, space and circumstances. The very conceptions of progress may have moved on to be understood in different terms.

Teacher biographies are typically characterized by engagements with a number of teaching approaches throughout any one career. Each shift from one to another entails mathematics being framed in a slightly different way that perhaps results in a different teaching style and, perhaps also, in a different conception of mathematics. Elements derived from each phase feed into composite experience and contribute to that teacher's modes of practice and emergent, and perhaps convergent, professional identity. These elements might be attributed variously to fashions in school practices, learning theories, assessment preferences, career phase of the individual teacher, etc. The shifts in teaching approach would normally be locally negotiated on the basis of some supposed improvement on the previous model.

Asking teachers to move from one teaching approach to another can, it seems, never be regarded as a straightforward substitution (c.f., Fullan, 2001). Nevertheless, for those charged with setting policy, there is often a perceived obligation to do something. And often this involves doing something big. In the United Kingdom, New Zealand and Australia, for example, governments have prescribed detailed curricula for students and teachers alike, along with associated industries concerned with preparing materials. Analogous to such support provision, the Chinese curriculum addresses the problem of scaffolding instructional innovation slightly differently. The mathematics curriculum itself contains sample activities, illustrative of approaches that Chinese teachers might employ in implementing the curriculum. Stateorchestrated textbook construction provides Chinese teachers with an authoritative body of definitions, explanations and tasks that can be interpreted confidently as embodying the aspirations of the official curriculum.

In terms of research literature, more information is readily available about the effect of major curriculum reform in the United States, where there is also a considerable emphasis on the widespread adoption of new curriculum materials as a primary strategy for improving mathematical education (Remillard, 2005; Remillard \& Bryans, 2004). Such is the extent and diversity of curriculum evaluation research in the USA that the National Research Council (USA) commissioned a meta-evaluation of mathematics curriculum evaluation studies (National Research Council, 2004). The report of this meta-evaluation proposed clear criteria for the conduct of curricular studies employing different methodological approaches. In addition to its substantive findings, the report provides a model of effective, scholarly consideration of curricular evaluation (see also US Department of Education, 2008),

The sheer volume of research carried out within the United States has resulted in the conceptions of teaching and curriculum implementation pertaining to this country seeping beyond 
its boundaries. Despite a diversity of context in the United States that defies simplistic summation, there is a sense in which it provides a context for the rest of the world. The country prescribes the parameters (through TIMSS, dominance in international research journals, setting political normalcy, promotion of the individual) whereby teaching might be classified, analyzed and informed. Ironically, American interest in Asian classrooms has stimulated a more widespread international interest in educational systems in the Asian region and encouraged researchers in Japan, China and Singapore, for example, to investigate their own practices and share the results with the international education community (Fan, Wong, Cai \& Li, 2004). The cultural specificity not only of the findings, but also of the educational value systems on which the findings are predicated, has perturbed the existing international acquiescence to a US-centric educational agenda. Emergent resonances of educational value and practice among European and Asian school systems may further destabilize the homogenization of international education threatened by the prominence of the international testing of student achievement and the educational imperialism of the OECD.

Conceptualizations of mathematical learning emerge through alternative curriculum models and development initiatives. Teachers, more or less, make sense of their practices adjusted in line with new descriptive lenses. They identify with successive curriculum models and the way in which these identifications frame mathematical learning. Within any curriculum implementation, both the teachers' sense of what they are doing and the curriculum itself are reconstituted through the encounter, thwarting any supposed convergence to an endpoint. This argument has implications for how we think about initiatives designed to work at creating consensus in teaching approaches. In particular, we need to question how or if research agenda encourage teachers to align with a particular model or philosophy of practice conceptualized in advance. Affinity with any particular model does not necessarily fix the mode of association or how that is viewed.

Remillard (2005, pp. 215-223) examined alternative ways in which teacher/curriculum interfaces have been understood within the research literature. She contrasted "following or subverting" a curriculum text with "drawing on" a curriculum text or "interpreting" a curriculum text. In these three alternatives, the text is present in some form and teachers respond to it. Finally, however, Remillard considered how curricula might be understood as teachers participating with the text. For a teacher "enacting" a curriculum in this mode, she suggested that teacher and curriculum might be seen as mutually constitutive. Here, curriculum use was understood as participation with the text (pp. 221-223). She identified this with "Vygotskian notions of tool use and mediation, wherein all human activity involves mediated action or the use of tools by human agents to interact with one another and the world" (c.f., Cole, 1996). Such an approach is familiar within mathematics education research (e.g., Blanton, Westbrook, \& Carter, 2005; Goos, 2005).

Ultimately, understood in terms of Foucault's (1989) notion of "discursive formation," both teacher and curriculum would be functions of how they are implicated in the stories that unite them. Both change as a result of curriculum development activity. Remillard (2005) identified some studies where teachers changed or learned from their use of resources (Lloyd, 1999; Remillard, 2000; van Zoest \& Bohl, 2002). Yet teacher change can also be understood as being the result of increased compliance with respect to a curriculum initiative. Aspirations to consensus can suppress the specificities of alternative needs, responses, etc, and thereby serve those who are already the most powerful. We find ourselves, yet again, cautioning against the possibility that research not only reproduces values pre-determined by the institutional context of the research, but also becomes complicit in the further reification of those values as universal.

\section{Publication Networks}

Journals of long-standing quality, serving different purposes and different audiences, such as Educational Studies in Mathematics, the Journal of Research in Mathematics Education, and 
For the Learning of Mathematics, continue to find a readership. Some journals, such as ZDMThe International Journal of Mathematics Education, successfully redefine their purpose and audience in addressing the concerns of the international research community in mathematics education. Other journals, such as the Journal of Mathematics Teacher Education, focus their efforts on a specialized readership within the mathematics education community. The viability of such journals is threatened by national measures that base their hierarchies on citation indices and impact factors.

Electronic publications have now established themselves within the field of recognized publication outlets. Government research productivity guidelines, such as that for the Excellence in Research for Australia, make no distinction among publications by mode of delivery and explicitly include e-books, for example, in the list of acceptable research publications. Such publications are subject to the same quality criteria as other forms of research output. Electronic publications have neither distorted nor diluted the quality of available outlets through which we might disseminate our research. Publication in electronic form now routinely precedes publication in hard-copy for most major journals and expedites the community's access to research.

High status conferences producing a published conference proceedings document employing a rigorous peer-review process can serve at least three essential functions: (a) Such conferences provide a forum at which the most topical issues and the most recent research can be reported and discussed; (b) The provision of an immediate publication outlet for the research reported at such conferences provides a more efficient documentation of advances in the field than that typically provided through the lengthy review and revision processes employed by journals; and (c) Provided the peer-review process is sufficiently rigorous, the resulting proceedings publication receives recognition within most measures of research productivity. The International Group for Psychology in Mathematics Education (PME) has long provided such a high-status research forum and publication outlet. Other conferences, such as the Congress of the European Society for Research in Mathematics Education (CERME), the Commission Internationale pour l'Étude et l'Amélioration de l'Enseignement des Mathématiques (CIEAEM, International Commission for the Study and Improvement of Mathematics Teaching) or the Research Pre-session of the annual conference of the National Council of Teachers of Mathematics (NCTM, USA), perceive their purposes differently and accord less priority to a peerreviewed proceedings publication, placing greater emphasis on providing an interactive forum, where the contribution of research to contemporary issues in mathematics education can be critically examined. Participation by members of the mathematics education community in major international conferences of a more general nature, such as the annual conference of the American Educational Research Association (AERA) or the biennial conference of the European Association for Research in Learning and Instruction (EARLI), provides an important connection between research in mathematics education and the general field of educational research. National and regional research conferences such as the Southern African Association for Research in Mathematics, Science and Technology Education (SAARMSTE), the Mathematics Education Research Group of Australasia (MERGA) and the East Asian Regional Conference On Mathematics Education (EARCOME) all provide opportunities for the reporting and discussion of research and all produce peer-reviewed conference proceedings of high quality.

\section{Academic Networking and Research Community Definition}

As with any other professional activity, mathematics education research is undertaken within a community membership that defines itself and the field through its research activities. Advances in technology have enabled entirely new forms of international research collaboration and thereby reconstructed research communities, both in terms of their membership and the nature of their activities. Regional networks have led to the establishment of major conferences 
such as EARCOME and SAARMSTE, mentioned above. The availability of a regional forum where research can be reported and possibilities explored for research partnership is an essential element in the promotion and maintenance of regional research networks. Independent of participation in more global international gatherings, regional conferences provide an opportunity to develop a regional research agenda, addressing issues more immediately pertinent to school systems in the region.

Participation in international research is constrained by many factors. One of these is access to the technological resources required to generate, store and analyze large data sets. Large databases generated by projects such as the Trends in International Mathematics and Science Study (TIMSS) and the Learner's Perspective Study (LPS) are now available to participating researchers anywhere in the world through high-speed, secure, web-mediated connection. Not only does this transform the nature of international research collaboration, by providing distributed access to storage facilities hosted within a single institution, less affluent research groups or institutions are saved the expense of costly storage facilities and are more able to participate in international research studies. It was previously noted that "when less affluent countries participate in international studies, it is frequently as the objects of investigation rather than as partners in the research" (Clarke, 2003, p. 177). Advances in technology and the growing emergence of international collaborative research networks are increasingly replacing such differentiated participation with true research partnership.

These emerging international research partnerships have the potential to catalyze a broadening in perceptions of the goals of research in mathematics education beyond the pragmatics of local utility. Recent curricular developments in Asian school systems, such as in China, Korea and Singapore, occur in parallel with advances through adaptation by countries such as the USA and Australia of approaches to instruction and teacher education originating in Japan and in China. These activities have been accompanied by the emergence of major research partnerships between researchers in Australia, the USA, and Europe with their counterparts in Japan, China, Korea and Singapore. This recognition of the mutual benefit afforded by international academic collaboration is an essential component in the reconceptualization of the mathematics education community as an international cross-cultural endeavour, of the manner in which research might be conducted and coordinated internationally, and of the contribution that research might make to particular school systems.

\section{The Training and Education of Researchers}

Mathematics education research is a function of the people who do it. At a local level a teacher might be concerned with doing research to teach in a more satisfying way at a personal level, or to develop or meet the demands of a school teaching scheme understood as shared guidance for a specific group of colleagues. At a national level research might be carried out by teacher educators addressing more generic issues, perhaps associated with externally defined targets or policy documentation. Or the research might be commissioned and shaped by administrators charged with managing a population of teachers and students through prescriptive curricular apparatus. At an international level, other aspirations may intervene, such as the need to speak effectively in an area of interest to a discernible group of researchers. In some countries, professional advancement in academic work is assessed by its perceived international status. Getting such an audience may be less about improving one's teaching or meeting an externally defined target through conforming to good practice, but more about learning to write or talk convincingly, even if it means neglecting one's teaching! Bordo (1999) argued that academia is often susceptible to mediatizing its image.

Academics sometimes use the accessories of theory (for example, specialised forms of jargon, predictable critical moves, references to certain authors) less in the interests of understanding the world than to proclaim themselves members of an elite club. In the process they create caricatures of 
themselves and of those who don't belong, peopling the scholarly world with typecast players and carving out narrow theoretical niches within which all ideas and authors are force-fit. Certain theoretical preferences, moreover, run throughout disciplines like incurable diseases, often carrying invisible racial and gender stereotypes and biases along with them. (p. 24)

A more charitable interpretation might be that academic fields get to be learnt through caricatures as it would be too overwhelming to do otherwise. Nevertheless, the impact of Bordo's comments seems to hold in educational research. The "production of educational theory and research is itself a site of ideological and political struggle" (Britzman, 2003, p. 68-citing McCarthy \& Apple; see also DeFreitas \& Nolan, 2008).

In parallel with the reconstruction of the international mathematics education research community, the mathematics education researcher has also undergone significant change. The contemporary researcher in mathematics education is much more likely to be well-versed in a variety of methodologies and theories than to be a doctrinaire adherent of a single theory or to engage in research restricted to a single methodological approach. In part, this ecumenical approach to research reflects the more team-driven nature of the contemporary enterprise. In many countries, such research teams combine researchers from a variety of cultural (and therefore educational) backgrounds, bringing usefully diverse perspectives to the research endeavour.

It has been changes to the institutional context of research, such as those already discussed, that have fuelled the reconstruction of the educational researcher from solitary worker to active member of a research community. It is to be hoped that the evolution of educational research (and mathematics education research, in particular) from cottage industry to international collegial enterprise will not discard cottage charm and individual creativity for a sort of industrialized and mechanical anonymity. Educational research will continue to draw many of its initiates from school settings, with a higher proportion of part-time involvement than would be found in early career researchers in the sciences. This part-time research community brings with it a vocational situatedness that should act to the benefit of the field of mathematics education research by locating research activity in the hands of those most likely to benefit from it and best placed to implement its findings.

The argument parallels that of the action-research community and appropriately so. Nonetheless, the participation of part-time research students presents challenges for the construction of a research community that universities and research centres address with uneven success. "There are significant difficulties in influencing the professional learning of educational researchers themselves towards changing the practices of educational research" (Rees, Baron, Boyask, \& Taylor, 2007). The slightly pessimistic note of this quotation should not lead us to disregard the advantages now available to the beginning researcher in mathematics education. The same technology that facilitates international networking can be exploited to create distributed research communities that integrate less and more experienced members in less and more vocationally-situated contexts. Rather, the recursiveness implicit in the research community's management of the on-going learning of its own constituents should be seen as an opportunity for continual regeneration and reflective interrogation rather than potential stagnation.

Available technologies offer the opportunity for early-career researchers to access the expertise of established researchers independent of the constraints of geography, culture or school system. Those responsible for the learning environments of beginning researchers have the opportunity to create and nurture richer, more interactive, and more diverse educational experiences for new members of the research community. The affordances provided by new connectivities and communicative networks act in the opposite direction to the constraining effects of some of the politically motivated dictates of legislation, accountability and funding provision discussed earlier.

The institutional context must be considered at least in local, national and international terms. With regard to the education of researchers, we have a tension between the local 
experience of improved access to the rich international diversity of theories, methodologies, issues, values, agendas, and research expertise and the potentially limiting influence of national and international political agendas (and ideological positions) that seek to channel research activity into officially sanctioned forms. In parallel with tensions in the framing of mathematics curricula, standardization in the name of accountability leads either to an impoverished curriculum offered to the beginning educational researcher or to a graduate community of mathematics education researchers, whose sophisticated research expertise is unable to be realized within the incentive schemes currently dominating the educational research landscape.

\section{Conclusion}

Mathematics education research typically seeks to inform the social interactive processes that locate but also transform teachers, students and mathematics. The task of such research can be understood from a range of perspectives that can mark out various operational levers, not just changes to teacher practice. As researchers we need to be aware of how our work is governed and formatted by a range of agencies, from employers allowing limited space between other duties, to funding agencies being specific about the perspectives they want to be depicted, to research assessment exercises or journals defining what is of value to the research community. But more generally we need to be attentive to the assumptions built into the locations of our work that restrict our scope of interest. The recommendations for practice arising from educational research are always situated recommendations, even if they are not presented as such.

Recognition of this emphasis on situated practice has implications for the sort of evidence likely to inform either educational policy or practice. Yet, the widespread enthusiasm for evidence-based policy development frequently begs the essential question as what constitutes evidence. Where this question is addressed, the answer may take the form of a prescription of valued and non-valued research paradigms. Publication of Scientific Research in Education by the National Research Council (USA) (Shavelson \& Towne, 2002) explicitly advocated "evidencebased education" and particularly encouraged research in the social sciences to adopt if not the methods at least the principles of medical research. Subscription to such a medico-scientific standard locates research and the researcher within a discourse predicated on the identification and evaluation of educational "treatments" as the focus of the research endeavour-classifying research participants as the doing and the done-to. This leads to an inevitable emphasis on "What works?" and the implication that this can be answered in some context-free fashion. The implied parallels between physiological phenomena and socio-cognitive phenomena suggest aspirations to a misleading generalizability that educational research can seldom justify except in the reporting of trivial descriptive findings. In contrast, the practitioner research tradition has sought to emphasize how research needs to be worked into practice through time.

Either educational research accepts a responsibility to express its findings in more practical terms, so that research evidence takes the form of endorsed practices, or research itself needs to be made a part of practice (Somekh, 2006). Research also needs to attend to the mediation of teacher education so that teachers can be prepared for particular understandings of practice. What teacher education programs would need to be put in place and how would this be achieved? There is little point having a thesis on "what works" if teachers cannot access this knowledge or are insufficiently skilled to bring it about.

Structural models are often seen, through cultural bias, as ones that should be aspired to more generally or internationally. For example, any given strategy implies resource constraints and one size fits all models potentially deny key aspects of diversity. Speaking from an African context, Swanson (2010, p. 245) asked the question: What are the implications for education and mathematics education, in particular, when industrialization and economic growth are the foremost policy objectives of a nation state? We have surveyed some of the implications in 
Western countries and those in the Pacific Rim. This, however, is only part of the picture. "Eighty per cent of the world's children are in developing countries. Yet, much of the research in mathematics education backgrounds this reality" (Adler, 2008, p. 241). Few schools/countries could supply the teachers who could offer the sensitivities and skills required in so many proposed models of mathematical learning (c.f., Skovsmose, 2005). For example, for all their rhetoric, U.S.-oriented liberal individualist constructivism and also Chinese authoritarian collectivism, support capitalism. Yet in answer to her own question, Swanson (2010) argued that this capitalism "has failed to provide the alluring 'rewards' for millions of people living in abject poverty who have little agency in relation to the hierarchy of access it has produced and which it serves to reproduce" (p. 246).

Students and teachers are not only (successful or unsuccessful) recipients of cultures but also creators of cultures insofar as their fresh perspectives on mathematical situations can be voiced, rather than being merely evaluated with respect to existing registers. Knijnik (2010) insisted on the intrinsic connection of mathematics education to culture. In discussing her work with the Landless Peasant Movement in Brazil, she described culture as a "conflictive, unstable and tense terrain, undermined by a permanent dispute to impose meanings through power relations" (p. 413), where the very concept of a unit of land remains contested. We need to ask what mechanisms might enable populations of teachers to support student creativity in challenging and renewing the cultures or contexts they occupy. As we have shown many facets of these cultures derive from externally imposed prescription, perhaps derived from norms that favour those in power.

Students and teachers are not things in themselves but are consequential to educational situations being read against specific discursive frames that shape the political domain and the priorities that domain confers. The term "teacher" for example, is constituted with respect to a particular social construction of that term and the expectations or aspirations that go with it, expectations and aspirations that differ markedly across schools and countries. As an individual teacher, I may have all sorts of personal optimism, but if I want a government job I have to fit in with the regulative structures pertaining to the context I am in, and understand myself through the terms of that regulation. Mathematics education research has a duty to enable teachers to assert a professionalism that meets yet transcends local regulative demands. To meet this duty we must reach beyond the context-specific meanings that research is obliged to service. Research might be seen as the task of rethinking mathematical teaching and learning with a view to changing them to meet or resist emerging demands. Through considering how teachers, teacher educators, trainees, pupils and researchers themselves make sense of their worlds, research can support work on how linguistic and socio-cultural contexts link to prevalent conceptions of mathematics education. Research itself can be seen as participation in cultural renewal, where the very worlds it encounters are becoming something new. This contemplates trajectories of change into fresh ways of being for teachers, teacher educators and researchers.

To represent mathematics as universal, spanning nations and generations, comes at a price. TIMSS and PISA were introduced to measure and compare school mathematics in different countries on a singular scale. Yet the resultant conceptions of school mathematics now define and police the boundaries of school mathematics. At a conference in 2011, a Mexican delegate spoke of how the exercises made her country subservient to American priorities for school mathematics (Garcia, Saiz \& Rivera, 2011). An Ethiopian educator depicted a situation in which teachers and students were obliged to engage with a form of mathematics encased in pedagogical formations largely unrecognizable in their country situation (Gebremichael, 2011). As seen, the United Kingdom has sacrificed its earlier facility with problem-solving approaches in order to meet newly understood "mathematical" objectives. Meanwhile, a Finnish commentator indicated that her country's high performance in the exercises did not release her colleagues from having to reevaluate their practices in terms of the newly dominant international discourse (Krzywacki, 
2011). School mathematical knowledge has come to be a function of this newly described world, backed up by governments using these conceptions of mathematics to set their policies.

Educational research distinguishes itself from research in the sciences by its tendency to recommend the replacement rather than the augmentation of existing practice. These new ways of understanding mathematics education that throw the baby out with the bath water deflect us from occupying alternative worlds, which might define us and serve us in different ways, according to priorities that may vary from one location to another. Excessive belief in unified objectives can simultaneously disregard more localized needs and corrupt the truly universal. Researchers have become complicit in promoting and reifying the values that support these particular conceptions of teaching and thereby restrict the trajectories for change that we are able to conceive. Also, research itself in many locations is increasingly obliged to follow formal regulation, setting the ways in which educational practices can be legitimately described. Since researchers in mathematics education are simultaneously members of the mathematics education community, they have become complicit in the construction of the field as an ideological battleground, in a terrain with features falsely identified as universal.

\section{References}

Adler, J. (2008). ICMI in Africa and Africa in ICMI: The development of AFRICME. In Menghini, M., Furinghetti, F., Giacardi, L., \& Arzarello, F. (Eds.) The first century of the International Commission on Mathematical Instruction (1908-2008): Reflecting and shaping the world of mathematics education (p. 236). Rome, Italy: Biblioteca dell'Enciclopedia Treccani.

Althusser, L. (1971). Ideology and ideological state apparatuses. In Lenin and philosophy and other essays. Translated and edited by B. Brewster. London, UK: New Left Books.

Anyon, J. (1981). Social class and school knowledge. Curriculum Inquiry 11(1), 3-42.

Askew, M., Hodgen, J. Hossain, S., \& Bretscher, N. (2010). Values and variables: A review of mathematics education in high-performing countries. London, UK: The Nuffield Foundation.

Bishop, A. (1990). Western mathematics: The secret weapon of cultural imperialism. Race and Class, 32(2), 51-65.

Blanton, M., Westbrook, S., \& Carter, G. (2005). Using Valsiner's zone theory to interpret teaching practices in mathematics and science classrooms. Journal of Mathematics Teacher Education, 8(1), 5-33.

Boaler, J. (1997). Experiencing school mathematics: Traditional and reform approaches to teaching and their impact on student learning. Buckingham, UK: Open University Press.

Bordo, S. (1999). Twilight zone: The hidden life of cultural images from Plato to O.J. London, UK: University of California Press.

Britzman, D. (2003). Practice makes practice: A critical study of learning to teach. Albany, NY: State University New York Press.

Brown, T. (2001). Mathematics education and language: Interpreting hermeneutics and poststructuralism (2nd ed.). Dordrecht, The Netherlands: Kluwer Academic Publishers.

Brown, T. (2011). Mathematics education and subjectivity: Cultures and cultural renewal. Dordrecht, The Netherlands: Springer.

Brown, T., \& McNamara, O. (2011). Becoming a mathematics teacher: Identity and identifications. Dordrecht, The Netherlands: Springer.

Brown, T., Devine, N., Leslie, E. Paiti, M., Sila'ila'i, E., Umaki, S., \& Williams, J. (2007). Reflective engagement in cultural history: A Lacanian perspective on Pasifika teachers in New Zealand. Pedagogy, Culture and Society, 15(1), 107-119.

Cai, J., \& Nie, B. (2007). Problem solving in Chinese mathematics education: Research and 
practice. ZDM-The International Journal of Mathematics Education, 39(5-6), 459-474.

Chazan, D., \& Ball, D. (1999). Beyond being told not to tell. For the Learning of Mathematics, 19(2), 2-10.

Cheng, Y. C., \& Cheung, W. M. (1999). Lessons from TIMSS in Europe: An observation from Asia. Educational Research and Evaluation, 5(2), 227-236.

Clarke, D. J. (1994). Why don't we just tell them? In C. Beesey \& D. Rasmussen (Eds.), Mathematics without limits (pp. 11-19). Brunswick, Victoria, Australia: Mathematical Association of Victoria.

Clarke, D. J. (1996). Assessment. In A. J. Bishop, M. A. Clements, C. Keitel, J. Kilpatrick \& C. Laborde (Eds.). International handbook of mathematics education (Vol. 1, pp. 327-370). Dordrecht, The Netherlands: Kluwer.

Clarke, D. J. (2003). International comparative studies in mathematics education. In A.J. Bishop, M. A. Clements, C. Keitel, J. Kilpatrick \& F. K. S. Leung (Eds.) Second international handbook of mathematics education (pp. 145-186). Dordrecht, The Netherlands: Kluwer.

Clarke, D. J. (2010). The cultural specificity of accomplished practice: Contingent conceptions of excellence. In Y. Shimizu, Y. Sekiguchi \& K. Hino (Eds.), In search of excellence in mathematics education: Proceedings of the $5^{\text {th }}$ East Asia Regional Conference on Mathematics Education (EARCOME5) (pp. 14-38). Tokyo, Japan: Japan Society of Mathematical Education.

Cohen, D. (1990). A revolution in one classroom: The case of Mrs Oublier. Educational Evaluation and Policy Analysis, 12, 327-345.

Cole, M. (1996). Cultural psychology: A once and future discipline. Cambridge, MA: Belknap Press.

Connell, R. (2007). Southern theory: The global dynamics of knowledge in the social sciences. Sydney, Australia: Allen and Unwin.

DeFreitas, E., \& Nolan, K. (2008). Opening the research text: Critical insights and in(ter)ventions into mathematics education. New York, NY: Springer.

De Lange, J. (1987). Mathematics, insight and meaning. Utrecht, The Netherlands: Freudenthal Institute.

Department for Education (DfE). (2010). The importance of teaching, London, UK: Author.

Fan, L., Wong, N-Y., Cai, J., \& Li, S. (2004). How Chinese learn mathematics: Perspectives from insiders. Hackensack, NJ: World Scientific.

Fan, L., \& Zhu, Y. (2007). From convergence to divergence: The development of mathematical problem solving in research, curriculum, and classroom practice in Singapore. ZDM-The International Journal of Mathematics Education, 39(5-6), 491-502.

Fennema, E., \& Nelson, B. (Eds.) (1997). Mathematics teachers in transition. Mahwah, NJ: Lawrence Erlbaum.

Foucault, M. (1989). The archaeology of knowledge. London, UK: Routledge.

Fullan, M. (2001). The new meaning of educational change (3rd ed.). New York, NY: Teachers College Press.

Garcia, R., Saiz, M., \& Rivera, A. (2011). Cognitive cultural analysis of low achievement in TIMSS: Evaluating wrong answers in $8^{\text {th }}$ grade. In B. Ubuz (Ed.), Proceedings of the $35^{\text {th }}$ Annual Conference of the International Group on the Psychology of Mathematics Education (Vol. 1, p. 382). Ankara, Turkey: Orta Dogu Teknik Üniversitesi [Middle East Technical University].

Gebremichael, A. (2011). Perceptions of relevance of prior experiences of mathematics in an Ehiopian preparatory school. In B. Ubuz (Ed.), Proceedings of the $35^{\text {th }}$ Annual Conference of the International Group on the Psychology of Mathematics Education (Vol. 1, p. 302). Ankara, Turkey: Orta Dogu Teknik Üniversitesi [Middle East Technical University]. 
Goodyear, P. (2005, December). What does international excellence in educational research look like? Paper presented at the Annual Conference of the Australian Association for Educational Research, held in Parramatta, New South Wales.

Goos, M. (2005). A sociocultural analysis of the development of pre-service and beginning teachers' pedagogical identities as users of technology. Journal of Mathematics Teacher Education, 8(1), 35-59.

Hargreaves, D. (1996). Teaching as a research-based profession: Possibilities and prospects. The Teacher Training Agency lecture. London, UK: Teachers Training Agency.

Hino, K. (2006). The role of seatwork in three Japanese classrooms. In D. Clarke, C. Keitel \& Y. Shimizu (Eds.), Mathematics classrooms in twelve countries: The insider's perspective (pp. 59-74). Rotterdam, The Netherlands: Sense Publishers.

Hino, K. (2007). Toward the problem-centred classroom: Trends in mathematical problem solving in Japan. ZDM-The International Journal of Mathematics Education, 39(5-6), 503-514.

Howson, G., \& Mellin-Olsen, S. (1986). Social norms and external evaluation. In B. Christiansen, A. G. Howson \& M. Otte (Eds.), Perspectives on mathematics education (pp. 1-48). Dordrecht, The Netherlands: Reidel.

Knijnik, G. (2010). Gelsa Knijnik's research on ethnomathematics. In M. F. Pinto \& T. F. Kawasaki (Eds.), Proceedings of the $34^{\text {th }}$ Annual Conference of the International Group for the Psychology of Mathematics Education (Vol. 1. pp. 413-415). Belo Horizonte, Brazil: International Group for the Psychology of Mathematics Education.

Krzywacki, H., Koistinen, L., \& Lavonen, J. (2011). Assessment in Finnish mathematics education: Various ways, various needs. In B. Ubuz (Ed.), Proceedings of the $35^{\text {th }}$ Annual Conference of the International Group on the Psychology of Mathematics Education (Vol. 1, p. 340). Ankara, Turkey: Orta Dogu Teknik Üniversitesi [Middle East Technical University].

Laclau, E. (2005). On populist reason. London, UK: Verso.

Lin, F-L. (2010). Mathematical tasks designing for different learning settings. In M. F. Pinto \& T. F. Kawasaki (Eds.), Proceedings of the $34^{\text {th }}$ Annual Conference of the International Group for the Psychology of Mathematics Education (Vol. 1. pp. 83-95). Belo Horizonte, Brazil: International Group for the Psychology of Mathematics Education.

Lloyd, G. M. (1999). Two teachers' conceptions of a reform-oriented curriculum: Implications for mathematics teacher development. Journal of Mathematics Teacher Education, 2(3), 227252.

Lobato, J., Clarke, D. J., \& Ellis, A. B. (2005). Initiating and eliciting in teaching: A reformulation of telling. Journal for Research in Mathematics Education 36(2), 101-136.

Mouffe, M. (2005). On the political. London, UK: Routledge.

National Research Council (2004). On evaluating curricular effectiveness: Judging the quality of K-12 mathematics evaluations. Washington, DC: National Academies Press.

National Research Council (2005). Advancing scientific research in education: Committee on Research in Education. In L. Towne, L. L. Wise \& T. M. Winters (Eds.). Title, page numbers???. Washington, DC: National Academies Press.

Otte, M. (1979). The education and professional life of mathematics teachers. In B. Christiansen \& H. G. Steiner (Eds.), New trends in mathematics teaching IV (pp. 107-133). Paris, France: UNESCO.

Pampaka, M., Williams, J., Hutcheson, G., Wake, G., Black, L., Davis, P., \& HernandezMartinez, P. (in press). The association between mathematics pedagogy and learners' dispositions for university study. British Educational Research Journal.

Radford, L. (2006). Elements of a cultural theory of objectification. Sudbury, Ontario, Canada: Université Lauentienne. 
Rees, G., Baron, S., Boyask, R., \& Taylor, C. (2007). Research-capacity building, professional learning and the social practices of educational research. British Educational Research Journal, 33(5), 761-781.

Remillard, J. (2000). Can curriculum materials support teachers' learning? Elementary School Journal, 11(4), 331-350.

Remillard, J. T. (2005). Examining key concepts in research on teachers' use of mathematics curricula. Review of Educational Research, 75(2), 211-246.

Remillard, J., \& Bryans, M. (2004). Teachers' orientations towards mathematics curriculum materials: implications for teacher learning. Journal for Research in Mathematics Education, 35(5), 352-388.

Remillard, J. T., \& Geist, P. K. (2002). Supporting teachers' professional learning by navigating openings in the curriculum. Journal of Mathematics Teacher Education, 5(1), 7-34.

Sammons, P., Day, C., Kington, A., Gu, Q., Stobart, G., \& Smees, R. (2007). Exploring variations in teachers' work, lives and their effects on pupils: Key findings and implications from a mixed-method study. British Educational Research Journal, 33(5), 681-701.

Saunders, L. (Ed.). (2007). Educational research and policy-making: Exploring the border country between research and policy. London, UK: Routledge.

Sekiguchi, Y. (2006). Mathematical norms in Japanese mathematics lessons. In D. J. Clarke, C. Keitel \& Y. Shimizu (Eds.), Mathematics classrooms in twelve countries: The insider's perspective (pp. 289-306). Rotterdam, The Netherlands: Sense Publishers.

Shavelson, R. J., \& Towne, L. (Eds.). (2002). Scientific research in education. Washington, DC: National Academies Press.

Shimizu, Y. (2006). How do you conclude today's lesson? The form and functions of "Matome" in mathematics lessons. In D. J. Clarke, J. Emanuelsson, E. Jablonka, \& I. Mok (Eds.), Making connections: Comparing mathematics classrooms around the world (pp. 127-145). Rotterdam, The Netherlands: Sense Publishers.

Simon, M., \& Tzur, R. (1999). Explicating the teacher's perspective from the researchers' perspectives: Generating accounts of mathematics teachers' practice. Journal for Research in Mathematics Education, 30(3), 252-264.

Skovsmose, O. (2005). Travelling through education: Uncertainty, mathematics, responsibility. Rotterdam, The Netherlands: Sense Publishers.

Somekh, B. (2006). Action research: A methodology for change and development. Maidenhead, UK: Open University Press.

Steffe, L., \& Kieran, T. (1994). Radical constructivism and mathematics education. Journal for Research in Mathematics Education, 25(6), 711-733.

Swanson, D. (2010). The paradox and politics of disadvantage. Narratizing critical moments of discourse and pedagogy within the "glocal." In M. Walshaw (Ed.) Unpacking pedagogy: New perspectives for mathematics classrooms (pp. 245-263). Greenwich, CT: Information Age.

Sztajn, P. (2003). Adapting reform ideas in different mathematics classrooms: Beliefs beyond mathematics. Journal of Mathematics Teacher Education, 6(1), 53-75.

Thorsten, M. (2000). Once upon a TIMSS: American and Japanese narrations of the Third International Mathematics and Science Study. Education and Society, 18(3), 45-76.

Törner, G., Schoenfeld, A. H., \& Reiss, K. M. (Eds.). (2007). Problem solving around the world: Summing up the state of the art. ZDM-The International Journal on Mathematics Education, 39 (5-6), 353-561.

Towne, L., Wise, L. L., \& Winters, T. M. (Eds.). (2005). Advancing scientific research in education. Washington, DC: National Academies Press. 
Tzur, R., Simon, M., Heinz, K., \& Kinsel, M. (2001). An account of a teacher's perspective on learning and teaching mathematics: Implications for teacher development. Journal of Mathematics Teacher Education, 4(3), 227-254.

United States Department of Education. (2008). Foundations for success: The final report of the National Mathematics Advisory Panel. Washington, DC: United States Department of Education.

van Zoest, L. R., \& Bohl, J. V. (2002). The role of reform curricular materials in an internship: The case of Alice and Gregory. Journal of Mathematics Teacher Education, 5, 265-288.

Walkerdine, V. (1984). Developmental psychology and the child-centred pedagogy. In J. Henriques, W. Holloway, C. Urwin, C. Venn, \& V. Walkerdine (Eds.), Changing the subject: Psychology, social regulation and subjectivity (pp. 153-202). London, UK: Methuen.

Whitty, G. (2006) Education(al) research and education policy making: Is conflict inevitable? British Educational Research Journal, 32(2), 159-176.

Wilson, S. M., \& Goldenberg, P. (1998). Some conceptions are difficult to change: One middle school mathematics teacher's struggle. Journal of Mathematics Teacher Education, 1, 269293.

Žižek, S. (2008). The plague of fantasies (2nd ed.). London, UK: Verso. 